\title{
A epidemiologia, os valores e o significado de paradigma
}

\author{
Epidemiology, values, and the meaning \\ of paradigm
}

Djalma Agripino de Melo Filho 1

1 Secretaria de Saúde de Pernambuco.

Rua Nunes Machado 119/603, Recife, $\mathrm{PE}$

50050-590, Brasil.
Abstract Use of the term paradigm has recently reached the epidemiological milieu. This articleprovides a critical analysis of a classification of "epidemiological paradigms" as proposed by Almeida-Filho. It was initially ascertained that values were not considered fundamental elements for the construction of paradigms, and that they therefore distanced themselves from the Kuhnian matrix. Systematization sought to unite antithetical tendencies and thus seemed closer to the Foucaltian epistéme. Finally, hegemony was consi dered a more appropriate term than paradigm for systematizing epidemiological periods, since the values of the different watersheds are committed to particularity (principally social class).

Key words Epidemiology; Philosophy; Epidemiologic Methods; Sociology

Resumo Recentemente, o emprego do termo paradigma chegou ao âmbito epidemiológico. Este texto analisou criticamente uma classificação de 'paradigmas epi demi ológi cos', proposta por Almei da-Filho. Ini cialmente constatou-se que os val ores não foram consi derados como el ementos fundamentais para a construção dos paradigmas, distanciando-se, assim, da matriz kuhniana. Uma vez quea sistematização procurou unir tendências antitéticas, el a pareceu estar mais próxi ma da epistéme foucaultiana. Finalmente, consi derou-se mais apropriada a utilização do termo hegemonia, em vez de paradigma, para sistematizar períodos epidemi ol ógi cos, pois os valores das vertentes estão comprometi dos com a parti culari dade (princi pal mente classe social). Palavras-chave Epidemiologia; Filosofia; Métodos Epidemi ológicos; Sociologia 


\section{Introdução}

No prefácio de sua célebre e polêmica obra, A Estrutura das Revoluções Científicas, Kuhn (1990:13) considera paradigma "as realizações científicas universal mente reconhecidas que, durante al gum tempo, fornecem problemas e soluções model ares para uma comunidade de praticantes de uma ciência".

A concepção pós-moderna de filosofia, ciência e arte, todavia, tentou propagar a idéia da relatividade dos parâmetros que elevariam a dóxa à condição de epistéme, impossibilitando, portanto, a construção de paradigmas. Sendo assim, a necessidade de ruptura com a particularidade e o consenso sobre a união do Verdadeiro, do Bem e do Belo para se alcançar a epistéme, defendido desde os antigos gregos, deveriam ser questionados.

Procurando ser fiel aos princípios da antiga tradição filosófica, este texto pretende analisar a classificação, elaborada por Almeida-Filho (1992), sobre paradigmas epidemiológicos, condensada em dois textos: "Os paradigmas da epidemiologia" e "Esboço de um novo paradigma para a epidemiologia", que compõem o livro A clínica ea epidemi ologia.

O primeiro deles é dividido em duas partes: na primeira, Almeida-Filho revisa e discute a categoria epistemológica de paradigma a partir de Kuhn (1990); na segunda, identifica, através de seus elementos essenciais, os paradigmas dominantes na epidemiologia. O segundo texto vislumbra a emergência de um novo paradigma.

Paradigmas epidemiológicos: a proposta de Almeida-Filho

Segundo Almeida-Filho (1992), A Estrutura das Revoluções Científicas, de Kuhn (1990), expõe basicamente três sentidos para o termo paradigma. O primeiro, próximo da concepção adotada pelo senso comum, faz referência a um padrão ou modelo a ser seguido. O segundo, considerado categoria epistemológica fundamental, constitui um instrumento de trabal ho para o cientista, possibilitando-o organizar o raciocínio, selecionar questões e fundamentar explicações em construções lógicas. O terceiro eúltimo sentido emerge do que se pode chamar de visão de mundo, segundo a qual o paradigma é composto por elementos formais e de conteúdo, caracterizados basicamente por generalizações simbólicas, desenhos de modelos heurísticos ou ontológicos e valores compartilhados por uma determinada comunidade científica.
Após os comentários teórico-conceituais, Almeida-Filho (1992) descreve a sua sistematização, onde são apresentados três paradigmas epidemiológicos. O primeiro, identificado com a causalidade, assume a doença, transposta da Clínica, como seu objeto e utiliza modelos causais cuja redução matemática é feita através de funções lineares simples, sendo a demonstração experimental o seu critério de prova. O segundo, reduto da maioria dos epidemiologistas, denominado de paradigma do risco, perscruta um objeto-resíduo, formado pela 'sobra' do que não é explicado pela determinação probabilística, utiliza funções lineares expandidas e seu potencial explicativo advém da predição. Por último, Almeida-Filho (1992) entrevê a emergência de um terceiro paradigma, alicerçado na criação de objetos totalizados, apreendidos através de model os de sistemas dinâmicos cuja eficácia explicativa provém da inferência estrutural, caracterizada eminentemente pela indeterminação.

Valores e paradigmas: uma relação necessária?

A fim de que se possam fazer algumas digressões entre val or e paradigma, é necessário recorrer, primeiramente, à filosofia que se embasa na tensão entre ser e dever, formando a unidade entre o Verdadei ro e o Bem, isto é, o dever-ser constituinte do "critério de medida de realidade ou não-realidade do ser", pois o próprio dever-ser "é de fato o el emento mais real" (Heller, 1983:16-7). A filosofia surge aqui como um guia necessário para que a ciência "desfetichize (ou desreifique) os sujeitos, a ação, a fala e a consciência dos seres humanos" (Heller, 1991: 214); tarefa difícil, embora inadiável, pois, a “generalização de uma consciência completamente fetichizada si gnificaria certamente o fim da fiIosofia" (Heller, 1983:10).

Existem, pois, dois tipos de recepção filosófica: a completa e a parcial. A primeira compreende, ao mesmo tempo, todos os três momentos da filosofia (a reflexão sobre o pensar, o agir e o viver). A segunda apreende somente um dos momentos, ela não é um fim em si mesma, mas um meio para produzir um outro efeito. A recepção completa engloba os seguintes subtipos: o receptor estético, quando a apropriação se faz através da forma, estimulando principalmente os sentimentos; o entendedor, quando se considera a filosofia um componente da cultura, compreendendo e interpretando os seus sistemas fil osóficos e, por último, o receptor filosófico, quando a apro- 
priação é feita filosoficamente, isto é, escoIhendo-se e vivendo-se uma filosofia (Heller, 1983).

Em relação à recepção parcial, também existem três subcategorias: quando se prioriza o momento relativo ao "como deves agir", falase em recepção política; quando se destaca o "como deves viver", a recepção torna-se 'iluminadora' e, quando se põe entre parênteses o "como deves pensar", a recepção é tomada como guia do conhecimento.

O nascimento da ciência moderna, inicialmente das naturais e posteriormente das sociais, possibilita a autonomia da modalidade de recepção como guia do conhecimento, haja vista o fato de os cientistas da natureza estarem, cada vez mais, utilizando a filosofia como balizadora das relações entre sua disciplina e a sociedade; com destaque, citam-se as discussões sobre as experiências com o núcleo atômico ou sobre a possibilidade de modificação do código genético (Heller, 1983).

No caso das ciências sociais, a utilização da filosofia dá-se, não só ultimamente, mas sempre, mesmo quando ela faltou ao seu compromisso: a psicologia de Freud e a sociologia de Weber e Durkheim criaram suas próprias filosofias. Sabe-se que a revelação e a ordenação de fatos sociais não constitui ciência, é necessária, todavia, "uma teoria queforneça a base para ligar os fatos e transformá-los, de dados, em fatos específicos da teoria" (Heller, 1983:49).

A ordenação, portanto, deverá ser feita não só através do método, mas também do valor. Enquanto aquele provém, na maioria dos casos, da filosofia ou das próprias ciências, este advém de duas fontes. A primeira encontra-se mergulhada na particularidade da consciência cotidiana, não liberta dos preconceitos. Criticar os valores advindos dessa fonte, com a finalidade de construir o conhecimento científico, não significa defender a neutralidade axiológica na teoria social, pois além de o intento não ser alcançável, o resultado final (caso o fosse) não seria, também, desejável. A segunda fonte, que busca romper com o imediatismo da vida cotidiana, refere-se a um "sistema devalores" ou a uma "hierarquia de valores de uma fiIosofi a e sua apli cação consci ente e autoconsciente na criação de uma teoria"; nesse sentido, os val ores estariam, agora de forma adequada e desejável, no cerne das teorias sociais (Heller, 1983:50).

Ao se proceder ao cotejamento da contribuição helleriana sobre a pertinência dos valores nas teorias com as reflexões de Almeida-FiIho relativas aos paradigmas epidemiológicos, verifica-se que, ao priorizar os aspectos emi- nentemente epistemo-metodológicos, a classificação de Almeida-Filho parece minimizar a importância dos valores, visto que eles se encontram ausentes do elenco de elementos de estruturação de sua proposta de classificação dos paradigmas em epidemiologia. Uma observação do próprio Kuhn (1990:224) é desfavorável a essa posição: “Um paradigma governa, em primeiro lugar, não um objeto de estudo, masum grupo de praticantes da ciência. Qualquer estudo de pesqui sas ori entadas por paradigma ou que levam à destruição de paradigma, deve começar pela localização do grupo ou grupos responsáveis".

Apesar da ausência dos valores em sua classificação, Almeida-Filho parece não aderir intencionalmente ao positivismo. Quando analisa a obra kuhniana, ele lembra que o paradigma "organiza el egiti ma valores compartil hados. (...) Por mais que os cientistas insistam em que constroem uma value freescience, Kuhn diz que isto não ocorre, que a prática científica se baseia em val ores bastante enraizados eem normas bem definidas, apesar de não-ditas" (Almeida-Filho, 1992:94).

A ausência de uma discussão sobre valores implica pelo menos dois riscos. O primeiro deles, assinalado na sociologia weberiana, referese ao fato que admite a conjunção de valores não refletidos, ou seja, valores identificados com a particularidade, com o conhecimento verdadeiro. O segundo deles, apontado na filosofia helleriana, reforça a tolerância com a simultaneidade de valores contraditórios dentro de um mesmo paradigma.

A partir dessa constatação, como explicar o fato de os valores não terem sido considerados para forjar os paradigmas epidemiológicos? Uma hipótese que poderia explicar essa elipse tenta aproximar a sistematização de AlmeidaFilho do estruturalismo foucaultiano, expresso em As Palavras e as Coisas, distanciando-a, todavia, do historicismo kuhniano.

\section{A antítese e o oxímoro:}

tensões entre Kuhn e Foucault

No estudo sobre as descontinuidades ocorridas na epistéme ocidental, renascentista, clássica e moderna, Foucault não busca especificidades, privilegia os aspectos sincrônicos dos discursos, recusa a reflexão sobre sua gênese, 'suturando' o que na aparência se mostra incoerente (Dosse, 1993).

O significado de paradigma, utilizado na classificação de Almeida-Filho, haja vista sua amplitude, poderia, fazendo os necessários 
ajustes, ser comparado com a epistéme foucaultiana: "Trata-se de verdadei ros surgi mentos, dilacerações, de que se contenta em anotar as modalidades e o lugar, sem se formular a questão deseu processo de emergência" (Dosse, 1993:373).

Os componentes da epistéme moderna estão, segundo Foucault, bem sincronizados, a ponto de o próprio marxismo integrar-se, sem turbulência, à placidez das águas de um imenso oceano epistêmico: “No nível profundo do saber ocidental, o marxismo não introduziu nenhum corte real; alojou-se sem dificuldade, como uma figura plena, tranqüila, confortável e, reconheça-se, satisfatória por um tempo (o seu), no interior de uma disposi ção epi stemológica que o acolheu favoravel mente (pois foi ela justamente quelhe deu lugar) e que ele não tinha, em troca, nem o propósito de perturbar nem sobretudo o poder de alterar, por pouco que fosse, pois que repousava intei ramente sobre ela. $\mathrm{O}$ marxismo está no pensamento do século XIX como peixe n'água: o que quer dizer que noutra parte qual quer deixa de respirar. Se ele se opõe às teorias 'burguesas' da economia e se, nessa oposi ção, projeta contra el as uma reversão radical da História, esse conflito e esse projeto têm por condição de possi bilidade não a retomada de toda a História nas mãos, mas um acontecimento que toda a arqueologia pode situar com precisão e que prescreveu simultaneamente, segundo o mesmo modo, a economia burguesa ea economia revolucionária do século XIX. Seus debates podem agitar algumas ondas e desenhar sulcos na superfíci e: são tempestades num copo d'água" (Foucault, 1990:277).

Tornando quase absoluta a dimensão sincrônica de suas estruturas, em detrimento dos aspectos diacrônicos, das mediações e dos processos de transformação e preferindo a 'geograficidade' à historicidade, Foucault e Almeida-Filho diluem, em seus respectivos 'oceanos', o que consideram esboços, prolegômenos, aporias e achegas de um discurso destituído de status de epistéme ou de paradigma.

Constata-se, na classificação de AlmeidaFilho, com base nas características atribuídas aos objetos investigados, a ausência de uma indicação precisa para o enquadramento do movimento da epidemiologia social. Talvez por considerá-la incapaz de ter construído um novo objeto a ser analisado através de instrumentos e tecnologias adequados e eficazes, Almeida-Filho, quando está fazendo algumas digressões sobre a emergência de um novo paradigma, diz: “Em muitos model os de investi gação da chamada epidemiologia social, por exemplo, propõem-se obj etos totalizados, si stemas dinâ- micos eabordagens processuais histórico-estruturais. E como se operacionaliza essa pretensão? Com a condução de estudos de caso, enquetes operárias e avaliações de dados secundários? $\mathrm{Na}$ minha opinião, desta forma produzem-se apenas cartas de intenções que não se cumprem com a descul pa de que os objetos são complexos e insubordinados eas técnicas são pobres ecomprometidas. Porém, na mesma epistemologia que fundamentaria tal justificativa (e que num futuro próximo todos compartil haremos, espero) diz-se que os objetos do conheci mento são mesmo complexos por definição, construídos pela prática eque as técnicas para a sua abordagem são por eledominadas" (Almeida-Filho, 1992:122).

Comentando as contribuições alternativas de Tambellini e Laurell, em relação à causalidade em Epidemiologia, Almeida-Filho (1989: 90) afirma: “Reconheço plenamentea provisoriedade de ambas as propostas (acredi to que os próprios autores já evoluíram em suas posi ções) e respei to profundamente o seu caráter de pioneirismo dadas as circunstâncias em que se apresentaram. Entretanto, creio que nenhuma delas preenche a ambi ção original de deslocar um sistema de proposi ções precedente, com o fim de substituí-lo por um sistema novo, de eficácia igual ou superior. Talvez o contexto da época em que emergi ram tenha prejudicado o seu potencial de contribuição ao debate em pauta".

Novas críticas, agora destinadas não só à proposta teórico-metodológica de Laurell, mas também à contribuição de Breilh, são feitas. Almeida-Filho (1993) diz que tanto uma, quanto outra buscam superar o conceito de 'risco', propondo outras noções como 'perfil epidemiológico de classe social', no caso de Breilh, e ‘nexo biopsíquico', no caso de Laurell; entretanto, suas propostas são, do ponto de vista teóricometodológico, insatisfatórias, principalmente a laurelliana que 'retorna' à noção clínico-fisiológica de 'perfil patológico individual'.

Será que o fato de Almeida-Filho considerar, em sua classificação, a ruptura com o conceito de risco como sendo uma condição necessária (e talvez suficiente) para o surgimento de um outro paradigma permitiria 'aninhar' como o fez Foucault com o marxismo, numa mesma estrutura, haja vista os invariantes já citados - os discursos: Epidemiology: Principles and Methods, de MacMahom \& Pugh, e Epidemiologia: Economía, Medicina y Política, de Breilh?

Todavia, da radicalização desse confronto, não se pode deduzir, como o subtexto dá a entender, a conclusão de que os supracitados au- 
tores estejam 'aninhados', também, axiologicamente; o que seria, sem sombra de dúvida, uma provocação esdrúxula, para não dizer mordaz. A intencionalidade no propósito visa provocar um espanto (thaumazein) a fim de se avultar a antítese, isto é, o aspecto diacrônico, ou o oxímoro que propõe revelar a possibilidade de essa característica ser, também, sincronizada.

\section{Considerações finais: o retorno a Kuhn}

A contribuição de Kuhn à teoria do conhecimento advém da análise histórica de descobertas e invenções exclusivamente ocorridas no campo das ciências naturais. Entretanto, diz ele: “Permanece em aberto a questão a respeito de que áreas das ciências soci ais já adquiri ram tais paradigmas. A História sugere quea estrada para um consenso estável na pesquisa éextraordinariamenteárdua" (Kuhn, 1990:35).

Desse fragmento, duas questões instigadoras poderão emergir. A primeira expressa uma dúvida: há paradigmas nas ciências sociais? A segunda parece proibir a existência simultânea de vários paradigmas dentro de uma mesma ciência, pois obter o status implica uma estabilidade, por isso é feito o alerta sobre a arduidade do caminho.

Tomando-se o objeto epidemiológico como sendo um objeto social e considerando-se apenas a primeira questão, poder-se-ia vislumbrar uma primeira saída. O envolvimento de valores em suas investigações, que são postas em prática dentro de uma sociedade baseada nas relações de subordinação e domínio, implicaria, aparentemente, a existência simultânea de vários paradigmas epidemiológicos (Barreto, 1990). Não obstante, essa não seria a melhor saída para o problema, pois além de cair no relativismo historicista das várias 'verdades', fortaleceria a tese da impossibilidade de construção de um saber verdadeiro (epistéme), havendo apenas uma opinião (dóxa). Tal solução estaria, em parte, também distanciada tanto de Kuhn como das origens gregas da filosofiaciência.

O segundo recurso seria fazer uma leitura (apressada) da segunda questão e admitir a possibilidade da vigência de um paradigma epidemiológico, vencedor da disputa com o seu antecessor, em cada um dos momentos históricos. Porém, antes de ir adiante, deverse-ia reconhecer que a leitura dinâmica tornou recôndito o 'consenso estável' implicando conseqüentemente a admissão de sua existência dentro das sociedades fundadas nas relações de subordinação e domínio. Segundo Breilh \& Granda (1985) e Breilh (1991), tal fato não se verifica na história da epidemiologia; por conseguinte, em termos kuhnianos, aparentemente, também não se poderia falar de paradigma epidemiológico. Na verdade o que é ou foi considerado paradigma tratar-se-ia realmente de uma hegemonia, no sentido gramsciano do termo (Bobbio et al., 1992), de uma das vertentes.

Nessa perspectiva, adotada por Breilh \& Granda (1985) e Rodrigues da Silva (1990), o discurso da epidemiologia social não estaria diluído em 'oceanos epistêmicos' cuja placidez estrutural parece ser eterna, sem calmarias. Tratando-o, ao contrário, como contra-hegemônico, já que não se pode, tendo em vista as críticas de Almei da-Filho, considerá-lo contraparadigmático, emerge, pelo menos, uma outra dimensão do problema, também epistemológica, relativa à discussão sobre conhecimento e valor verdadeiros produzidos em sociedades de subordinação e domínio de classes, de gêneros etc.

Finalmente, retornando-se à classificação proposta por Almei da-Filho, constata-se que o significado de hegemonia ou contra-hegemonia, em vez de paradigma, é mais adequado para sistematizar a epidemiologia, pois os valores embutidos nas diversas vertentes (até agora) estão comprometidos com a particularidade (principalmente de classe social), distanciando-se, portanto, da universalidade do valor e do conhecimento verdadeiros. 


\section{Referências}

ALMEIDA-FILHO, N., 1989. Epidemiologia sem Números: Uma Introdução Crítica à Ciência Epidemiológica. Rio de Janeiro: Campus.

ALMEIDA-FILHO, N., 1992. Os paradigmas da epidemiologia. In: A Clínica ea Epidemiologia (N. Almeida-Filho, org.), pp. 90-104. Rio de Janeiro: Abrasco.

ALMEIDA-FILHO, N., 1993. La investigación y la practica de la epidemiologia en America Latina: desafios teóricos y metodológicos. Taller sobre Estudio de la Situación de Salud segun Condiciones deVida. Salvador. (mimeo.)

BARRETO, M. L., 1990. A epidemiologia, sua história e crises: notas para pensar o futuro. In: Epidemiologia: Teoria e Objeto (D. C. Costa, org.), pp. 1938, São Paulo: Hucitec/Rio de Janeiro: Abrasco.

BOBBIO, N.; MATTEUCCI, N. \& PASQUINO, G., 1992. Dicionário de Política. Vols. 1 e 2, 4a ed., Brasília: Editora Universidade de Brasília.

BREILH, J. \& GRANDA, E., 1985. Os novos rumos da epidemiologia. In: As Ciências Sociais em Saúde na América Latina: Tendências e Perspectivas ( $E$. D. Nunes, org.), pp. 141-53, Brasília: Organização Panamericana de Saúde.
BREILH, J., 1991. Epidemiologia: Economia, Política e Saúde. São Paulo: Unesp/Hucitec.

DOSSE, F., 1993. História do Estruturalismo: O Campo do Signo, 1945/1966. Vol. 1, São Paulo: Ensaio/Campinas: Editora UNICAMP.

FOU CAULT, M., 1990. As Palavras e as Coisas: Uma Arqueologia das Ciências Humanas. 5ạ ed., São Paulo: Martins Fontes.

HELLER, A., 1983. A Filosofia Radical. São Paulo: Brasiliense.

HELLER, A., 1991. A sociologia como desfetichização da modernidade. Novos Estudos CEBRAP, 30:214.

KUHN, T. S., 1990. A Estrutura das Revoluções Científicas. 3a ed., São Paulo: Perspectiva.

RODRIGUES DA SILVA, G., 1990. Avaliação e perspectivas da epidemiologia no Brasil. In: Anais do I Congresso Brasileiro de Epidemiologia (Associação Brasileira de Pós-Graduação em Saúde Coletiva - Abrasco, org.), pp. 108-39. Campinas: Abrasco. 